\title{
Editorial: Four Score (Plus) Years Ago
}

\section{Etzel Cardeña}

Among their many achievements, Joseph Banks Rhine and collaborators launched The Journal of Parapsychology (JP) in 1937, the foremost venue for parapsychology experimental research and surpassed in longevity only by the Journal of the Society for Psychical Research. There had been important controlled studies in parapsychology earlier on, but J. B. Rhine and his collaborators placed experimental parapsychology on a more secure footing. The eighty-plus years of JP issues would constitute an extraordinary achievement in any field, but is even more remarkable in such a contentious area as parapsychology. To avoid repeating mistakes one should be cognizant of the field's previous history (Cardeña, 2018a) and even a cursory look at the JP indexes shows how the field has developed throughout the years. My intention for this Supplementary E-issue was to give a bird's eye view of the coverage in the JP. My selection of articles will not make everyone completely happy but I trust that it will not make everybody surly either. My criteria to select articles for this issue were to: a) have an article per decade, 2) cover most of its main areas, 3) avoid having more than one article by the same author, and 4) include papers by important women and men, giving their right due to the former (Cardeña, 2018b).

I have left the original papers with very little reformatting and excluding addresses, which are now obsolete. This issue starts with two new papers I commissioned for the issue. In the first one, the previous editor, John Palmer, who very likely knows more about the JP than anyone, provides a general overview, focusing on some of the major controversies and debates covered in it, including how J. B. Rhine's original policy not to publish non-supportive papers was challenged from within the field.

The second one, by the most prolific parapsychology historian nowadays, Carlos Alvarado, sketches the diversity of topics and approaches covered by the JP throughout the years, changes in editorial emphases, and how the JP has contributed to the field overall.

The first archival paper is by Joseph Banks Rhine, the most recognized figure in the experimental approach to psi phenomena in the middle of the $20^{\text {th }}$ century. His article is characteristic of the approach of his group, a meticulous account of carefully designed very extensive sets of studies ("selected from our present stock of several hundred thousand trials") that thoroughly tested alternative non-psi explanations, improved methodology in answer to valid criticisms, and vigorously refuted invalid critiques. One of his observations, echoed by more recent research (e.g., the Nelson paper in this issue) is that in one series participants were more accurate in the first and last sections, reminiscent of the primacy and recency effects in recall of newly learned material. The fact that the paper had originally been published in the foremost journal on abnormal psychology then (and now), exemplifies how close he came to making parapsychology a mainstream accepted area of study. 
Next is a paper by Gardner Murphy, who was not only the President of the (British) Society for Psychical (SPR) but of the American Psychological Association (APA). He authored a narrative, qualitative analysis of data relevant to possible survival, discussing how difficult it is to definitely rule out whether relevant data can be explained through psi by the living, while simultaneously pointing out to the potential motivation by discarnates as the explanation for some communications, a discussion very much alive in our days (e.g., Braude, 2003; Sudduth, 2016). By the way, one of the most important psychologists of all time, William James, was also president of the SPR and APA, and a founder of the American Society for Psychical Research. More recently Philip Zimbardo, another APA past-president, is on record for supporting an informed study of psi phenomena (Cardeña, 2014).

The next contribution is by the other great Rhine, Louisa, who focused on systematically collecting, organizing, and analyzing reports of spontaneous putative psi phenomena, following the tradition of the Society for Psychical Research's landmark Phantasms of the Living (Gurney, Myers, \& Podmore, 1886). Her paper has various examples of the four categories she found in most spontaneous reports and has a number of theoretical speculations that have not been fully mined. There are excellent reasons and bodies of knowledge (e.g., the research on CORT, or Cases Suggestive of the Reincarnation Type, see Kelly \& Tucker, 2015) to justify the thorough investigation of putative psi phenomena occurring outside the lab. Louisa E. Rhine had also the rare ability of being an excellent popularizer of the field for the general audience (e.g., L. E. Rhine, 1967).

From qualitative emphases we move to the hard sciences, with physicist Helmut Schmidt and his landmark description of the new PK/precognition methodology he developed, involving the intentional anomalous deviation from randomness of random event generators he devised. In addition to this new method, he went on to publish other original and challenging works such as the one in which he described retroactive PK effects (Schmidt, 1976). Varvoglis and Bancel (2015) have described how using "selected subjects" (see also the Utts paper in this issue) and being procedurally flexible encourages better performance by participants.

And from physics we move to psychology and an area that deserves more attention, the sociocultural and neurocognitive variables potentially related to psi. Gertrude Schmeidler wrote many papers and books seeking to integrate mainstream psychology with parapsychology (e.g., Schmeidler, 1988) and we owe her, among other things, the finding that those who believe in the existence of psi ("sheep") tend to manifest slightly but significantly higher scores than those who do not hold such belief ("goats'). This effect has been replicated in meta-analyses (e.g., Storm \& Tressoldi, 2017) and, of course, does not make any sense unless humans can somehow cognize stimuli temporally or spatially distant, otherwise there would not be any significant difference between the two groups. I do not think that currently any psi researcher is looking at brainwave biofeedback and psi, but some studies have found a relation between alterations of consciousness and performance in psi tasks (for a review see Cardeña \& Marcusson-Clavertz, 2015).

One of the most celebrated papers in parapsychology is the collaboration between a psi-critic (Ray Hyman) and a psi-proponent (Charles Honorton). Rather than continuing to argue with each other, they collaborated on a landmark article citing their agreements and disagreements and proposing improvements to and standardization of ganzfeld methodology and reporting. Meta-analyses of research following such guidelines have continued to support a valid effect for ganzfeld research (for a review 
see Cardeña, 2018c). They mention that "The critic can contribute to this need only if his criticisms are informed, relevant, and responsible," conditions that I have found to be rather rare in many if not most of the criticisms of psi research.

Another discipline that has been fundamental to psi is statistics. Parapsychology has made important contributions to research methodology and the use of statistics, including the first systematic use of meta-analysis (Pratt, Rhine, Smith, Stuart, \& Greenwood, 1940). The paper included is by the 2016 President of the American Statistical Association, Jessica Utts. In it, she provides a thorough analysis of the psi program conducted at SRI (Stanford Research International) and SAIC (Science Applications International Corporation), taking into consideration methodological weaknesses. However, she failed to mention that contra a criticism of the SRI Price series, later research by Tart, Puthoff, and Targ (1980) found that extraneous cues in the transcripts did not explain away the significant results. She concludes that, although anomalous cognition cannot be demonstrated on demand, as so many other skills in life, "anomalous cognition is possible and has been demonstrated... No one who has examined all of the data across laboratories, taken as a collective whole, has been able to suggest methodological or statistical problems to explain the ever-increasing and consistent results to date." In the same issue she published her paper there was a long rebuttal by the critic Ray Hyman (1995). His comments are at times reasonable. For instance, I fully agree that it is a losing cause to define psi negatively, as phenomena lacking scientific explanation or not explained by conventional means, whereas a reasonable hypothesis is that consciousness (or mind, to include conscious and unconscious processes) is not fully bound by temporal and spatial constraints. Other criticisms are, in my view, untenable, and he gives an idealized version of science that is not only not true of the soft sciences, but even of the hard sciences. In a reply to his rebuttal, Utts (1995) belies Hyman's statements that parapsychology lacks a cumulative database, that psi phenomena are the only ones in science that claim ontological reality by rejecting the null hypothesis, and that parapsychology is the only field of science in which students cannot be assigned an exemplar in class in which they will be able to get original results. The last point is particularly obvious for anybody in academia. In my many years of advanced education not only in psychology but also in behavioral developmental genetics, psychophysiology, anthropology, and other disciplines, other than some easy experiments in psychophysics and learning with caged rats I was never exposed to what Hyman declares to be a characteristic of science pedagogy.

The final paper, by Roger Nelson, provides an excellent antidote to the often-voiced criticism that nothing has been found or developed in parapsychology in more than a century. In contrast, he gives a detailed list of what was developed and found by the Princeton Engineering Anomalous Research (PEAR) group, which was foundational for the later development of the Global Consciousness Project (the GCP). The GCP evaluates whether the output of random number generators distributed throughout the globe can be affected by changes in consciousness in the population following an attention-grabbing event such as the 9/11 attacks (Nelson updated this information in Nelson, 2015). The GCP is also an example of research with big and open data, which very few projects in any areas of science can boast of, and yet another example that psi does have a cumulative database.

Nelson's optimistic forecast of the future of parapsychology is also a good note to finish this celebration of the 80 years of the Journal of Parapsychology. May the reader be at least as inspired and impressed by reading these past contribution as I have been. I want to thank a number of people for 
their assistance with this issue. I sent a call for nominations of the most important JP articles from its inception, and the following provided useful suggestions, even if I did not always heed them: Carlos Alvarado, Roger Nelson, and Nancy Zingrone. Thank you also to John G. Kruth for arranging the scanning of the original articles and to Daryl Junk for doing the scanning and initial editing.

\section{References}

Braude, S. (2003). Immortal remains: The evidence for life after death. Lanham, MD: Rowman \& Littlefield.

Cardeña, E. (2014). A call for an open, informed, study of all aspects of consciousness. Frontiers in Human Neuroscience, doi: 10.3389/fnhum.2014.00017.

Cardeña, E. (2018a). Keeping up is hard to do. [Editorial]. Journal of Parapsychology, 82, 5-7. http://doi. org/10.30891/jopar.2018.01.01

Cardeña, E. (2018b). uuxń is a woman. Journal of Parapsychology, 82, 99-101. doi.org/10.30891/ japar.2018.02.01

Cardeña, E. (2018c). The experimental evidence for parapsychological phenomena: A review. American Psychologist, 73(5), 663-677. https://doi.org/10.1037/amp0000236

Cardeña, E., \& Marcusson-Clavertz, D. (2015). States, traits, beliefs, and psi. In E. Cardeña, J. Palmer, \& D. Marcusson-Clavertz (Eds.). Parapsychology: A handbook for the 21 $1^{\text {st century }}$ (pp. 110-124). Jefferson, NC: McFarland.

Gurney, E., Myers, F. W. H., \& Podmore, F. (1886). Phantasms of the living (Vols. 1-2). London, UK: Trübner. Hyman, R. (1995). Evaluation of the program on anomalous mental phenomena. Journal of Parapsychology, 59, 321-351.

Kelly, E. W., \& Tucker, J. B. (2015). Research methods with spontaneous case studies. In E. Cardeña, J.

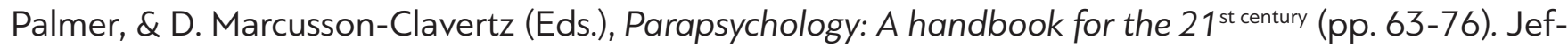
ferson, NC: McFarland.

Nelson, R. D. (2015). Implicit physical psi: The global consciousness project. In E. Cardeña, J. Palmer, \& D. Marcusson-Clavertz (Eds.), Parapsychology: A handbook for the 21 $1^{\text {st }}$ century (pp. 282-292). Jefferson, NC: McFarland.

Pratt, J. G., Rhine, J. B., Smith, B. M., Stuart, C. E., \& Greenwood J. A. (1940). Extra-sensory perception after sixty years: A critical appraisal of the research in extra-sensory perception. New York: Henry Holt.

Rhine, L. E. (1967). ESP in life and lab: Tracing hidden channels. New York: Colliers.

Schmeidler, G. R. (1988). Parapsychology and psychology: Matches and mismatches. Jefferson, NC: McFarland.

Schmidt, H. (1976). PK effect on pre-recorded targets. Journal for the American Society for Psychical Research 70, 267-291.

Storm, L., \& Tressoldi, P. E. (2017). Gathering in more sheep and goats: A meta-analysis of forced-choice sheep-goat ESP studies, 1994-2015. Journal of the Society for Psychical Research, 81, 79-107.

Sudduth, M. (2016). A philosophical critique of empirical arguments for postmortem survival. London, UK: Palgrave Macmillan.

Tart, C. T., Puthoff, H. E., \& Targ, R. (1980). Information transmission in remote viewing experiments. Nature, 284, 191.

Utts, J. (1995). Response to Ray Hyman's report "Evaluations of the program on anomalous mental phenomena." Journal of Parapsychology, 59, 353-356.

Varvoglis, M., \& Bancel, P. A. (2015). Micro-psychokinesis. In E. Cardeña, J. Palmer, \& D. Marcusson-Clavertz (Eds.), Parapsychology: A handbook for the $21^{\text {st }}$ century (pp. 266-281). Jefferson, NC: McFarland. 